\title{
Psychological Support of Adolescent after Autocastration: A Case Report
} Anastasia Polkovnikova-Wamoto, Manasi Kumar* and David Bukusi

University Of Nairobi, Nairobi, Kenya

\begin{abstract}
Previous case reports on autocastration have focused mostly on psychiatric and surgical (urology) interventions since most of such individuals appear overtly psychotic and require serious medical involvement due to the nature of their trauma. The importance of psychological support after stabilization has been largely overlooked. This paper describes an adolescent who was followed up for 2 years after an act of autocastration emanating from a religious based ordering hallucination.
\end{abstract}

\section{Introduction}

Instances of Genital Self-Mutilation (GSM) where varying amounts of tissues get amputated is a very rare phenomenon. Blacker and Wong [1] reported 40 cases worldwide since the beginning of the last century and according to Mago [2] the number had increased to only 110 cases by 2011 . It has been reported that in approximately $10 \%$ of the cases, GSM includes the total amputation of the penis, scrotum and testes [3].

Probably one of the very first cases of male GSM was described in Greek myth about the God Eshmun who castrated himself to escape the amorous pursuit of the Goddess Astronoe (Astarte); this is how autocastration was named the Eshmun Complex [4]. Researchers also distinguish two subtypes of self-mutilation that is "van Gogh syndrome" and "Klingsor syndrome" [5]. The first one refer to any self-mutilation under the influence of an ordering hallucination [6]; the second to autocastration as a consequence of religious delusions [7].

People practice self-injury from ancient times as a mean of mergence with their god, or at least to replace their old identity with a new one which is pure and closer to god [8]. Religious exponents of this rare phenomenon can be traced back to ancient Rome where clerics considered this practice as "a supreme sacrifice of sexual life in favor of the emotion to the highest known good" [9]. The New Testament also has a verse about male GSM in Mathew 19:12: "There are eunuchs born that way from their mother's womb, there are eunuchs made so by men, and there are eunuchs who have made themselves that way for the sake of the Kingdom of Heaven." All researchers seem to agree that majority of the reported cases of GSM occur in psychotic individuals. The proportions reported are slightly different: Greilsheimer and Groves, [10] found the presence of psychosis in $87 \%$ of a study of cases, while Romilly and Isaac [3] found psychosis in $66 \%$ of all cases reviewed. To the best of our knowledge psychological support in such severe case of GSM for the patient under 20 has never been reported.

This case study describes the case of an adolescent who was followed up closely for over two years. The patient was seen as the outpatient in psychiatry clinic 4 (four) months after self-castration up until the first stage of penile restorative surgery.

\section{Case Report}

A 16-year-old male patient, who amputated his penis, scrotum and testes with a kitchen knife and had thrown it into the toilet, following religious based ordering hallucination, is presented in this report. The patient was referred to the outpatient psychiatric youth clinic after he spent 3 months in the surgical urology wards. After two months stay he ran away from the hospital but he was found after it was reported to the police and re-admitted to the same hospital for another one month.

According to the patient's father, boy had started behaving "like a mad man" two months prior to the act of self-mutilation - "He was walking aimlessly and laughing to himself, became rude and disobedient." The young boy confirmed the same time period - two months before self-mutilation - as the time when he had started using marijuana (Cannabis sativa) (2 cigarettes per day) plus khat (also known locally as mirrah) and 5-6 bottles of beer (especially on Sundays), and subsequently started seeing and hearing "demons."

He developed grandiose delusions consisting of the religious themes that appeared at the same time as the hallucinations. The patient believed that he was "to suffer in Africa for Africans same like Jesus. He would go to the heaven and would be equal to Jesus. Jesus could be leader for white people and he would be leader for Africans. It was indicated that he must not marry, same like Jesus. He was a man of God, he was a prophet. For him to be saved he had to cut himself and he would be ended with the world. If he would not cut himself the world would end and he would remain and continue suffering." All his actions including self-castration and his escape from the hospital have been attributed to orders/instructions from "demons" that he could see and hear at that time.

The patient is the only son in a family of eight; his father is a carpenter and has his own small workshop while his mother sells vegetables in a kiosk. The parents together with the patient and their three unmarried daughters live in their rural house. The parents could not recall any history of psychiatric or medical illnesses among close relatives from the both sides of the family.

When interviewed by AP and Dr. DB, the patient reported both auditory and visual hallucinations; yet he did not demonstrate any gross disorganization of thought. His speech was articulate, his thoughts were well formed, and his manners were helpful. He denied the autocastration as being an attempt to change his gender identity. On the contrary, after hospital when he went home he realized what he had done and that he "was no longer man" and at that time he thought about killing himself. He had a plan of hanging or throwing himself into water. Church and social support made him change his mind. His mood was severely depressed; he cried few times while talking about what he had done to himself and that "he was no longer a man". At that time of interview he did not report any suicidal ideation, suicidal behavior, or desire for

*Corresponding author: Manasi Kumar, University Of Nairobi, Nairobi, Kenya, Tel: +254 (0) 717379687; E-mail: manni_3in@hotmail.com

Received February 27, 2015; Accepted April 13, 2015; Published April 15, 2015

Citation: Polkovnikova-Wamoto A, Kumar M, Bukusi D (2015) Psychological Support of Adolescent after Autocastration: A Case Report. J Clin Case Rep 5: 521. doi:10.4172/2165-7920.1000521

Copyright: (C) 2015 Polkovnikova-Wamoto A, et al. This is an open-access article distributed under the terms of the Creative Commons Attribution License, which permits unrestricted use, distribution, and reproduction in any medium, provided the original author and source are credited. 
self-injury. Initially a diagnosis of Substance/Medication -Induced Psychotic Disorder with onset during intoxication with hallucinations [11] was made with incipient schizophrenia as a differential diagnosis.

\section{Management}

In the course of the following four weeks from the intake the patient was compliant with his medication and the visual hallucinations gradually subsided, but the auditory hallucinations together with 'buzz$\mathrm{z}-\mathrm{z}$ ' sound continues especially when he was alone/idle or even when people were around but he was not involved with them. So during the seventh session (almost two months from the intake) the first author, AP, suggested to the patient to think of an experiment, whereby they sat quietly and wait for voices to appear, and indeed these voices did appear after five minutes of silence. Then AP suggested that he could write a small essay: "The most wonderful day in my life." He wrote it for around seven minutes and reported no voices while writing. So it was suggested that he could write short stories for his small nieces and nephews.

Apart from working with hallucinations, as it was suggested by Dr. MK, different aspects of "manhood" were continuously discussed with the patient starting from the third session, which resulted in the patient's involvement in family home-chores such as fetching water, helping with heavy shopping amongst other errands.

The patient reported good improvement in his general well-being after implementing writing exercises together with manual house work. All of this received a positive feedback from various family members. At this point the adolescent told AP that "it helped him to work towards acceptance of himself and helps him feel better about himself."

Three weeks after, the patient's daily schedule of activities was reassessed. Together with the psychologist, the patient came to a realization that he was still very idle and had lots of time at home that better utilized. Joint brain storming resulted in a list of educational, leisure and money-generating activities.

At the intake (4 (four) months after autocastration) the patient had partial insight. In the course of supportive therapy together with psychiatric stabilization it took the patient a further three [3] months to get full insight into the implications of what he had done to himself. As a result, the patient started developing symptoms of Post-traumatic Stress Disorder (PTSD) with Delayed Onset, symptoms started eight [8] months after self-mutilation, including: recurrent and intrusive recollection of event in form of thoughts and images, nightmares about the same, flashbacks, difficulties related to sleep and concentration, attempts to avoid thoughts and feeling associated with traumatic event. A decision was made to initiate TF-CBT (Trauma Focused Cognitive Behavioral Therapy) as an intervention. The model of trauma focused CBT used here was developed by J.A. Cohen and colleagues for use with children and adolescences.

The implementation proceeded as follows: Stress inoculation therapy followed by gradual exposure was introduced after general psycho-education about stress, scientific and common sense basis for psycho-trauma therapy. The patient was taught deep breathing technique with visualization, progressive muscle relaxation and thought stopping techniques. Gradual desensitization to incident was achieved through re-writing the account of events. The patient reported that the first write-up was very hard. Indeed he experienced a lot of resistance and negativity towards therapist (according to his own account he was annoyed, questioning authority of the therapist to put him through such exercises, and wanted to stop writing about it) in the process of doing it but by the time he was writing the last one ( 9 weeks later) he said that he thought mostly of how to make it more readable and give as many details as possible. The patient was very emotional and cried few times when he was reading his first account of the incident. Finally, when reading the last entry he did appear relaxed. The final story itself was longer and had more information, he was also spontaneously adding up extra details after every few sentences in the course of reading.

Due to the complex and multifaceted nature of the trauma the patient was concurrently attending urology and plastic surgery outpatient clinics. In order to get a deeper understanding of the physiological issues and outcomes of his case, Dr. MK (clinical psychologist) and Dr DB (psychiatrist) suggested that AP accompany the patient during those visits in order to correspondingly adjust the psychotherapeutics based on an immediate feedback from the findings and planning of the respective urology and plastic surgery clinics.

Subsequently the mental health team managed to persuade medical professionals that this patient did not have concerns of transgender identity; the patient was put on a waiting list for corrective surgery on a "project" whereby surgeons from various developed countries came together to perform complicated operations locally (in Kenya) for educational and charity purposes.

There was marked anxiety over the outcomes of the surgery, some of these included: when would the first surgery would be scheduled, how many surgeries will be required, what were the possible side-effects, what would be the intermediate and final outcomes of those surgeries, would the surgery completely restore a functional anatomical unit among other social and relational anxieties. CBT with a specific focus on this 'correct surgery' was offered to the patient and the psychologist worked on the negative cognitions, reasoning and addressing patients' queries on outcomes and the patient's lack of basic knowledge about human anatomy and medicine were the core themes.

By the end of the first six months of the therapy the focus of psychologists' sessions had started gradually shifting from the past and present as a specific theme period to the present and the future. The patient admitted that, although, he had still been feeling very low at times when he thought about the past he had also started thinking about future including about when he could get married and adopt children and have a family of his own. As a result any returning to the discussion of "manhood" from that point on included aspect of "fatherhood" and its' composites. Along with the patient the psychologist worked on appreciating his skills and capabilities as opposed to concentrating on what he lacked, specifically addressing ways of compensating for his shortcomings and challenges. Also discussed were different options and strategies which he could potentially employ regarding his sex-life.

By the end of the ninth month of the therapy the patient relapsed. He had stopped taking all his medication following the advice from his local pharmacist. Both visual and auditory hallucinations re-appeared together with delusions including. "thoughts broadcasting", having "a hole in his head", feelings of " a melting head", "people getting inside of him", etc. He wrote a list of twenty issues which were disturbing him since he had stopped medication. It was suggested to use that list as a custom-made tool to assess his progress after he re-started his pharmacological treatment which proved to be successful.

In order to reassure his further compliance with medication the psychiatrist together with the psychologist took the patient to the main pharmacy in the referral hospital, where the young man was given information about the importance of taking prescribed medication by the head pharmacist. In addition, he was told that he was jeopardizing his chances for any surgery since before the surgery he would have to 
have a satisfactory independent psychiatric examination. He promised not to repeat his non-adherence.

During the following psychotherapy sessions the same list of symptoms was used to review his progress. The number of symptoms got reduced and by the end of the fourth month from the relapse mainly four symptoms remained:

- He felt that his head was open

- That people could enter him

- When people were talking and moving hands he felt as if they were touching him or being inside his head

- He had doubts about his memory

Over a period of time (after stabilization following the relapse), the patient reported that he was able to separate when he was feeling as if he was touched (as an abnormal perception) and when he was actually being touched by someone. This also applied for other three symptoms he said that he knew that it is just these feelings and they were not true.

Seven months after relapse and sixteen months after the initial intake, two symptoms remained: "The opening in the head" and "the feeling that people were touching him when they were gesturing". The patient reported gradual habituation to those feelings. He said that he used other senses to differentiate actual physical sensation from the one which was generated in his head. E.g. when people are gesticulating while talking to him, he could see that they did not touch him and those feelings of being touched were not true sensations but generated by his head.

After discussions within the mental health team and in the context of the patient acknowledging that he could tell the difference between reality and when he was having abnormal perceptions, it was suggested to work with the patient towards acceptance of that particular symptomatology while hopefully awaiting resolution that might actually take a long time.

The last few months before the actual corrective surgery with the patients frustration had to be worked on implementing strategies including, "one step at a time" as a way of thinking and continued to think positively as the operation was rescheduled 4 times. The patient eventually had the operation and when seen after the surgery he seemed tired but he also seemed satisfied with the outcome. All the major steps he had successfully negotiated to reach the post- operation stage were reviewed with the patient agreeing and accepting that it had been a long journey indeed, and that the journey ahead might even be longer. Continuous psychotherapeutic support was still going to be very necessary and his therapy still continues.

\section{Discussion}

Most of available information about genital injury related to medical aspect of the trauma. According to Frappell-Cooke and colleagues at the moment "there is no published evidence base to guide psychological interventions for genital trauma". Publications on the impact of such injury on individual are also scarce [12]. In the described case substance induced psychosis and self-infliction of the injury adds up to the complexity of the clinical picture. Taking into consideration all mentioned above eclectic approach to the therapy with regular assessments and re-adjustments of it depend on patient's progress and information from urology and plastic surgery teams was accepted as the only possible.

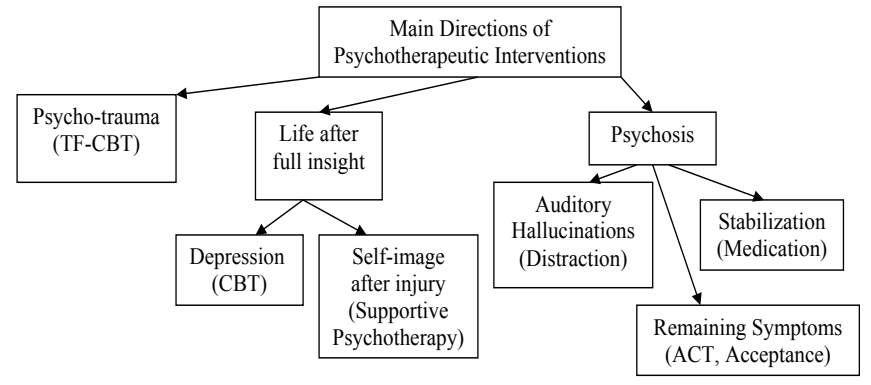

Figure 1: Main directions of psychotherapeutic interventions.

Reflecting on the main aspects of the psychotherapy we came up with three main directions: psychosis, psycho-trauma and life after full insight (Figure 1).

The very first and obvious step at the beginning of the therapy was psychiatric stabilization of the patient. After it was achieved and patient gained insight into his mental and physical post-injury condition number of important aspects of patient's well-being emerged: continuation of auditory hallucinations (including noises), some psychotic symptoms remain (e.g. feeling of "opening in the head"), new symptoms of delayed PTSD, depressive symptoms related to understanding of life-long consequences of severe genital injury - "loss of future".

After repeated attempts to control voices/noises via adjusting medication decision was made to try behavioral approach. Literature describes different types of distractions as a coping strategy for people suffering from auditory hallucinations including: hobbies, reading, listening music, watching TV [13], running [14], actively looking for company of other people [15], talking to somebody [16], socializing, task performance [17]. In the case described patient found especially useful in dealing with auditory hallucinations story writing, task performance (house hold shores) and socializing. Probably because by performing those activities he was not only divert his attention from unpleasant and disturbing voices/noises but also was able to serve the family needs and correspondingly got extra positive feedbacks from family members.

Due to uniqueness of the case and also in an attempt to be more culture-sensitive it was suggested to use patient-made list of symptoms as a mean of progress assessment. It proved to be successful practice because it gave possibility to discuss complex phenomena on the patient's language and it serve as additional incentive in medication compliance making the patient to feel in control while he was comparing his own lists of symptoms.

Acceptance component of Acceptance and Commitment Therapy (ACT) [18] was used to work with remaining symptoms, whereby the accent was shifted from elimination of remaining symptoms to learning how to live with them.

After relative stabilization and at the beginning of gaining full insight the patient developed full set of delayed PTSD symptoms. Adaptation of TF-CBT was chosen for of the following reasons. First it is a well-known, empirically supported treatment model which has been designed specifically for children and adolescents [19]. Secondly it was easy to adapt TF-CBT for specific psycho-trauma context without compromising its integrity $[20,21]$. Thirdly the techniques used in the course of the therapy did not require a high educational level from the 
patient (patient's highest achieved level of education is 8 years of formal education - Primary School) and thus this appeared appropriate to implement in this case here

The last aspect of the therapy "life after insight" was probably the hardest one. The bare minimum of available information, about possible surgical interventions and likely outcomes of those in lowincome settings, made planning of the therapy sessions extremely very difficult. Cognitive Behavioral Therapy (CBT) was employed as the most appropriate option [22] taking into consideration the age of the patient and that after full insight he developed classical clinical picture of Major Depressive Disorder [11] including low mood, crying spells, fatigue, poor appetite, sleep disturbances and feeling of worthlessness. Before patient has got placement for "the project" following techniques were used: relaxation, daily and weekly scheduling of activities; Automatic Negative Thought Diary; work with malfunctioned cognitions related to "manhood", future, family life, etc. During the waiting time before surgery CBT helped to work on developing frustration tolerance and dispel negative cognitions related to anesthesia and surgery itself.

\section{Conclusion}

The existing data suggest that self-harm in adolescents is an important public health concern. Published reports suggest a $13-18 \%$ lifetime prevalence of self-injurious behavior in young people [10,2325], but genital self-mutilation with poly-substance use in adolescence, to the best of our knowledge, has never been described. Moreover, we have not found any reports of psychological support of such patients before, during and after medical and psychiatric stabilization. This particular case captured an adolescent patient with Genital SelfMutilation (GSM) brought to the attention of the mental health team following discharge from a surgical ward. What brought the patient to the clinic was his psychiatric symptomatology. The mental health team, using psychiatric and psychotherapeutic techniques worked on both managing his psychopathology - his psychotic symptoms as well as psycho-stabilization and adaptation - based on the outcomes of the GSM, the treatment for the psychosis, the corrective surgery, the psychosocial adaptation following psychiatric treatment as well as setting up a framework to address both psycho-rehabilitation and post corrective care surgery and psychosocial adaptation. We hope future reports will provide more information on post-stabilization psychotherapeutic support for severe self-mutilation patients.

\section{References}

1. Blacker KWN (1963) Four cases of autocastration. Archives of General Psychiatry 8: 169.

2. Mago V (2011) Male genital self-mutilation. Indian J Psychiatry 53: 168-169.

3. Romilly CS, Isaac MT (1996) Male genital self-mutilation. Br J Hosp Med 55: 427-431.

4. Kushner AW (1967) Two cases of auto-castration due to religious delusions. Br J Med Psychol 40: 293-298.

5. Waugh AC (1986) Autocastration and biblical delusions in schizophrenia. $\mathrm{Br} \mathrm{J}$ Psychiatry 149: 656-658.

6. Vafaei B (2003) Two case reports of self-mutilation or van Gogh syndrome. Acta Medica Iranica 41: 199-201.

7. Carroll PR, Lue TF, Schmidt RA, Trengrove-Jones G, McAninch JW (1985) Penile replantation: Current concepts. J Urol 133: 281-286.
8. Glucklich A (2001) Sacred Pain: Hurting the Body for the Sake of the Soul. New York: Oxford University.

9. Rajendra BN, Ravish IR, Shrishailesh SA, Manoranjan UD, Vikram P, et al (2008) Genital self-mutilation in non-psychotic heterosexual males: Case report of two cases. Indian J Psychiatry 50: 285-287.

10. Greilsheimer H, Groves JE (1979) Male genital self-mutilation. Arch Gen Psychiatry 36: 441-446.

11. Frappell-Cooke W, Wink P, Wood A (2013) The psychological challenge of genital injury. Journal of the Royal Army Medical Corps 159: 52-56.

12. Lucas PA, Page PR, Phillip RD, Bennett AN (2014) The impact of genital trauma on wounded servicemen: qualitative study. Injury 45: 825-829.

13. Fallon IR, Talbott RE (1981) Persistent auditory hallucinations: Coping mechanisms and implications for management. Psychol Med 11: 329-339.

14. Romme MA, Honig A, Noorthoorn E, Escher A (1992) Coping with hearing voices: An emancipator approach. British Journal of Psychiatry 161: 99-103.

15. O'Sullivan K (1994) Dimensions of coping with auditory hallucinations. Journal of Mental Health 3: 351-361.

16. Nayani TH, David AS (1996) The auditory hallucination: A phenomenological survey. Psychol Med 26: 177-189.

17. Bak M, van der Spil F, Gunther N, Radstake S, Delespaul P, et al. (2001) Assessment of Coping Strategies (MACS-I): A brief instrument to assess coping with psychotic symptoms. Acta Psychiatr Scand; 103: 453-459.

18. Hayes SC, Strosahl KD, Wilson KG (2013) Acceptance and Commitment Therapy: An Experiential Approach to Behavior Change, (2ndedn), New York: The Guilford.

19. Cohen JA, Mannarino AP, Kliethermes M, Murray LA (2012) Trauma-focused CBT for youth with complex trauma. Child Abuse and Neglect 36: 528-541.

20. Murray LK, Dorsey S, Skavenski S, Kasoma M, Imasiku M, et al. (2013) Identification, modification, and implementation of an evidence-based psychotherapy for children in a low-income country: the use of TF-CBT in Zambia. International Journal of Mental Health Systems 7: 24.

21. Murray LK, Skavenski S, Michalopoulos LM, Bolton PA, Bass JK, et al. (2014) Counselor and client perspectives of Trauma-focused Cognitive Behaviora Therapy for children in Zambia: a qualitative study. Journal of Clinical Child and Adolescent Psychology 43: 902-914.

22. Dolle K, Schulte-Körne G (2013) Clinical practice guideline: The treatment of depressive disorders in children and adolescents. Dtsch Arztebl Int 110: 854860.

23. Evans E, Hawton K, Rodham K, Deeks J (2005) The prevalence of suicidal phenomena in adolescents: a systematic review of population-based studies. Suicide Life Threat Behav 35: 239-250.

24. Kidger J, Heron J, Lewis G, Evans J, Gunnell D (2012) Adolescent self-harm and suicidal thoughts in the ALSPAC cohort: A self-report survey in England. BMC Psychiatry 12: 69.

25. Madge N, Hewitt A, Hawton K, de Wilde EJ, Corcoran P, et al. (2008) Deliberate self-harm within an international community sample of young people: comparative findings from the Child \& Adolescent Self-harm in Europe (CASE) Study. J Child Psychol Psychiatry 49: 667-677. 